\title{
In vitro growth and maturation of pig oocytes
}

\author{
Y. Hirao ${ }^{1}$, T. Nagai ${ }^{2}$, M. Kubo ${ }^{3}$, T. Miyano ${ }^{4}$, M. Miyake ${ }^{4}$ and \\ S. Kato ${ }^{4}$ \\ ${ }^{\mathrm{I}}$ The Graduate School of Science and Technology, Kobe University, Nada-ku, Kobe 657, Japan; \\ ${ }^{2}$ Department of Animal Reproduction, National Institute of Animal Industry, Tsukuba, Ibaraki \\ 305, Japan; ${ }^{3}$ Pathological Diagnosis Laboratory, Systemic Diagnosis Research Division, National \\ Institute of Animal Health, Kannondai-1, Tsukuba, Ibaraki 305, Japan; and ${ }^{4}$ Laboratory of \\ Animal Reproduction, Faculty of Agriculture, Kobe University, Nada-ku, Kobe 657, Japan
}

\begin{abstract}
Preantral follicles containing oocytes of $70-89.5 \mu \mathrm{m}$ in diameter were isolated from pig ovaries and cultured in collagen gel for up to 16 days, in the presence of serum, FSH and oestradiol. Formation of follicular antra occurred as the culture proceeded. The oocytes had been enclosed by granulosa cells and contacts between the oocytes and processes of the enclosing cumulus cells were maintained over the culture period. After 16 days of culture, $30-40 \%$ of the oocytes were of normal appearance, and the diameters of about half of these oocytes were larger than $100 \mu \mathrm{m}$. When the oocytes grown in vitro were liberated from the follicles and cultured for a further $48 \mathrm{~h}$ in modified Krebs-Ringer bicarbonate solution, 6, 30 and $60 \%$ of the oocytes larger than 90,100 and $110 \mu \mathrm{m}$ underwent germinal vesicle breakdown, respectively. Progression to metaphase II was observed in $40 \%$ of oocytes that were over $110 \mu \mathrm{m}$ in diameter, whereas no oocyte less than $90 \mu \mathrm{m}$ in diameter resumed meiosis. The relationship between the size and meiotic competence of oocytes was similar for oocytes grown in vitro or in vivo. Oocytes grown and matured in vitro were penetrated by spermatozoa and formed a female pronucleus, but decondensation of the sperm head was incomplete. The results demonstrate for the first time that pig oocytes from preantral follicles can grow up to their final size, acquire meiotic competence, and be penetrated by spermatozoa in vitro.
\end{abstract}

\section{Introduction}

In mammalian ovaries, oocytes begin to grow and increase in diameter while the nucleus remains in the first meiotic prophase. After the preovulatory surge of gonadotrophin, only fully grown oocytes can resume meiosis, complete the first meiotic division, and are ovulated. Although a large number of oocytes are present in ovaries (Gosden and Telfer, 1987), only a very small population of oocytes becomes available for ovulation, and most of the oocytes are lost at various stages of growth in the ovary.

In vitro culture of oocytes isolated from ovaries has been thought to be potentially useful for oocytes that are lost owing to atresia of follicles (Eppig et al., 1990). The fully grown mammalian oocytes isolated from antral follicles can mature, be fertilized and develop into live young in mice (Schroeder and Eppig, 1984), rats (Vanderhyden and Armstrong, 1989), sheep (Staigmiller and Moor, 1984), cattle (Goto et al., 1988) and pigs (Mattioli et al, 1989).

Recently, in vitro culture techniques for growing oocytes of rodents have been improved to assist investigation of the mechanisms of oocyte and follicular development. Under appropriate conditions, meiotically incompetent oocytes from preantral follicles can grow to final size and complete nuclear maturation in vitro (Eppig, 1977; Eppig and Downs, 1987; Daniel et al., 1989; Hirao et al., 1990; Carroll et al., 1991). Furthermore, successful production of live young from oocytes that have been grown and matured in vitro demonstrates that the oocytes can acquire full developmental capacity in vitro (Eppig and Schroeder, 1989; Eppig et al., 1992).

For livestock production, culture of growing oocytes could provide a large population of female germ cells. In the study reported here, a culture system is described that will support the growth of pig oocytes from mid-growth stage to final size. Such oocytes acquire the capacity to resume and complete the first meiotic division and be penetrated by spermatozoa.

\section{Materials and Methods}

\section{Collection of preantral follicles}

Ovaries were collected from prepubertal gilts at a local abattoir and transported to the laboratory within $I \mathrm{~h}$, while preventing any abrupt temperature changes. The ovaries were washed with PBS and Eagle's minimum essential medium (MEM; Nissui Pharmaceutical Co., Ltd, Tokyo), Hepes (Nacaiai Tesque, Inc., Kyoto) buffered with, and cut into small pieces 
$(2-3 \mathrm{~mm})$ with a blade. The pieces were incubated in Hepesbuffered MEM containing $0.1 \%$ collagenase (Wako Pure Chemical Industries, Ltd, Osaka) for $\mathrm{I} \mathrm{h}$ at $39^{\circ} \mathrm{C}$. After the treatment, preantral follicles were removed from the connective tissues and freed from adherent thecal cells using fine forceps and a needle. Follicles with diameter of $0.2-0.3 \mathrm{~mm}$ were collected with a mouth-operated fine pipette and washed three times with Hepes-buffered MEM containing $2 \%$ fetal calf serum (FCS; Filtron Ltd, Victoria). Each follicle was transferred into a microdrop of the medium under paraffin oil, and the diameters of oocytes (excluding zona pellucida) were measured with an ocular micrometer attached to an inverted microscope. Only follicles containing oocytes with diameters of $70-89.5 \mu \mathrm{m}$ were used for the culture.

\section{Culture of follicles and recovery of oocytes}

Freshly isolated follicles were separated into two classes according to oocyte diameter, 70-79.5 and $80-89.5 \mu \mathrm{m}$, and were cultured for 16 days and 12 days, respectively. Collagen gel solution was prepared by mixing $0.3 \%$ acid-soluble collagen solution (Cellmatrix-I: Nitta Gelatine Co. Ltd., Osaka), ten times concentrated Waymouth MB752/1 medium (Sigma Chemical Co., St Louis, MO) without bicarbonate, and $0.05 \mathrm{~mol} \mathrm{NaOH} \mathrm{l}{ }^{-1}$ containing $22 \mathrm{mg} \mathrm{NaHCO} \mathrm{ml}^{-1}$ and $47.7 \mathrm{mg}$ Hepes $\mathrm{ml}^{-1}$, at concentration 8:1:1 (v:v:v). Isolated follicles were washed three times in the culture medium (described below), and five follicles in a small volume of medium were placed in the centre of a plastic dish ( $35 \mathrm{~mm} \times 10 \mathrm{~mm}$; Falcon, Becton Dickinson Labware, Lincoln Park, NJ) and overlaid with $0.4 \mathrm{ml}$ of the collagen gel solution. When the collagen gels had set after incubation for $20 \mathrm{~min}$ at $39^{\circ} \mathrm{C}, 3 \mathrm{ml}$ of the culture medium was poured into the dishes. The follicles were cultured at $39^{\circ} \mathrm{C}$ under an atmosphere of $5 \%$ $\mathrm{CO}_{2}$ and $95 \%$ air. The culture medium used was Waymouth MB752/I supplemented with $50 \mu \mathrm{g}$ sodium pyruvate $\mathrm{ml}^{-1}$ (Nacalai Tesque, Inc.), $100 \mu \mathrm{g}$ penicillin $\mathrm{ml}^{-1}$ (Penicillin G potassium; Meiji Conf. Co., Tokyo), $50 \mu \mathrm{g}$ streptomycin $\mathrm{ml}^{-1}$ (Streptomycin sulfate: Meiji Conf. Co.), 5\% FCS, 2 miu $\mathrm{FSH} \mathrm{ml}^{-1}$ (from porcine pituitary; Sigma Chemical Co.) and $1 \mu \mathrm{g}$ oestradiol $\mathrm{ml}^{-1}$ (Sigma Chemical Co.). Supplementation of both hormones supported follicular growth in vitro in the preliminary experiments. One-half of the medium was changed every 4 days. At the end of the culture, the collagen gel matrices were treated with $0.1 \%$ collagenase solution and the follicles were recovered. Oocytes collected from the follicles were denuded by pipetting and their growth and morphology were examined under an inverted microscope. Oocytes in which the ooplasm was deformed and disintegrated were considered as degenerated. The diameters of oocytes with normal appearance were measured with an ocular micrometer.

Some follicles were fixed in $4 \%$ formaldehyde in phosphate buffer after culture for histological examination. For light microscopy, the fixed follicles were dehydrated and embedded in JB-4 (Polysciences Inc., Warrington, PA). They were serially sectioned by $2 \mu \mathrm{m}$, stained with periodic acid-Schiff and haematoxylin, and examined. For electron microscopy, follicles were post-fixed in osmium tetroxide. They were then dehydrated, embedded in epoxy resin (Luveak 812; Nacalai Tesque,
Inc.), and serially sectioned into ultrathin sections. The follicles were stained with uranyl acetate and lead citrate, and examined under an electron microscope (1200EX; Jeol, Tokyo).

\section{In vitro maturation and fertilization of oocytes}

In the second experiment, the maturational competence of oocytes grown in vitro was assessed. The follicles containing oocytes with diameters of $70-89.5 \mu \mathrm{m}$ were cultured for 16 days as described previously. After culture, the oocytes enclosed by one or two layers of cumulus cells were collected from the follicles, washed three times with modified Krebs-Ringer bicarbonate (mKRB) solution (Toyoda and Chang, 1974) and transferred into microdrops (10 $\mu \mathrm{l})$ of the solution covered with paraffin oil in a plastic dish ( $60 \mathrm{~mm} \times 15 \mathrm{~mm}$; Falcon). They were cultured for $48 \mathrm{~h}$ at $39^{\circ} \mathrm{C}$ in $5 \% \mathrm{CO}_{2}$ and $95 \%$ air; oocytes that had acquired meiotic competence would undergo spontaneous maturation. As a control, oocyte-cumulus cell complexes isolated from ovarian follicles with diameters less than $3 \mathrm{~mm}$ were used. After measurement of diameters of the oocytes, they were cultured in the same manner. After $48 \mathrm{~h}$, some of the oocytes were denuded mechanically and mounted on slides. They were then fixed in acetic alcohol, stained with $1 \%$ acetoorcein and examined for the stage of meiotic maturation under a phase-contrast microscope.

The remaining oocytes were transferred into microdrops $(100 \mu \mathrm{l})$ of the fertilization medium, BO solution (Brackett and Oliphant, 1975) containing $10 \mathrm{mg} \mathrm{BSA} \mathrm{ml}^{-1}$ (Sigma Chemical Co.) and $2 \mathrm{mmol}$ caffeine $1^{-1}$ (Sigma Chemical Co.), and covered with paraffin oil. The oocytes were inseminated by epididymal boar spermatozoa using the method described by Nagai et al. (1988) with some modifications. Frozen spermatozoa were thawed in TCM 199 (Gibco, Grand Island, NY) containing $3 \mathrm{mg} \mathrm{BSA} \mathrm{ml}-1$ at $37^{\circ} \mathrm{C}$. The suspension was centrifuged for $3 \mathrm{~min}$ at $700 \mathrm{~g}$, and the supernatant was discarded. The spermatozoa were resuspended in TCM 199 ( $\mathrm{pH} 7.8$ ) containing 12\% FCS. After another washing with centrifugation, the spermatozoa were diluted with the same medium to a concentration of $2-4 \times 10^{8}$ cells ml ${ }^{-1}$, and the suspension was incubated for $30 \mathrm{~min}$ at $37^{\circ} \mathrm{C}$ under an atmosphere of $5 \% \mathrm{CO}_{2}$ and $95 \%$ air. A portion of the preincubated sperm suspension was introduced into the fertilization medium containing oocytes grown in vitro, so that the final concentration of spermatozoa was $2 \times 10^{6}$ cells ml $^{-1}$, and cultured at $39^{\circ} \mathrm{C}$ in $5 \% \mathrm{CO}_{2}$ and $95 \%$ air. Ten hours after insemination, the oocytes were mounted on slides, fixed in acetic alcohol and stained with $1 \%$ aceto-orcein to ascertain sperm penetration and formation of pronuclei.

\section{Results}

\section{Oocyte growth in vitro}

Oocytes at mid-growth phase were clearly visible in all preantral follicles isolated from the ovaries (Fig. I). In the follicles embedded in the collagen gels, oocytes were enclosed in granulosa cells throughout the culture period. The follicles grew in the gels, in particular those that developed an antral 


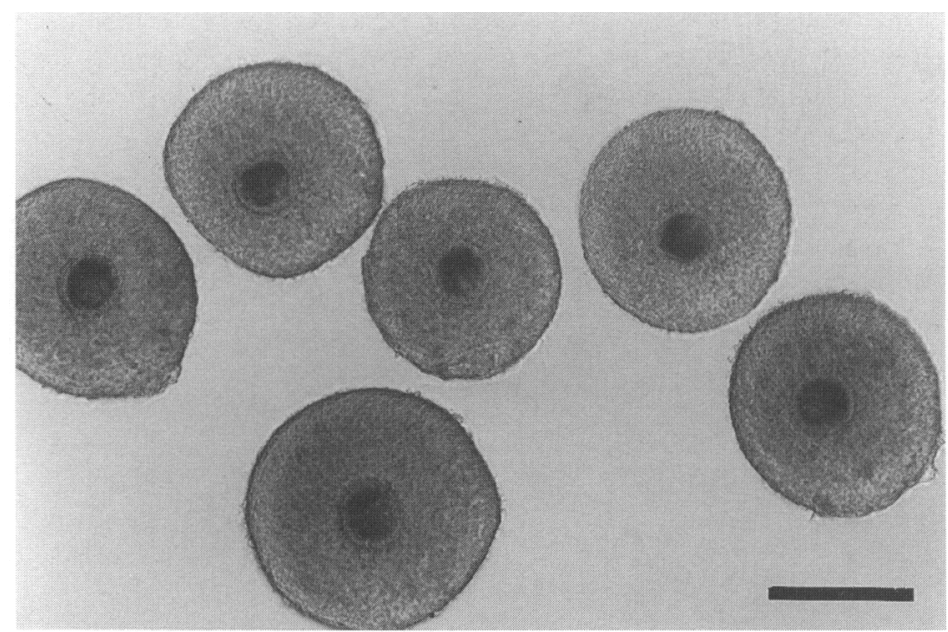

Fig. 1. Preantral follicles isolated from pig ovaries. Oocytes are visible in follicles. Bar represents $200 \mu \mathrm{m}$.

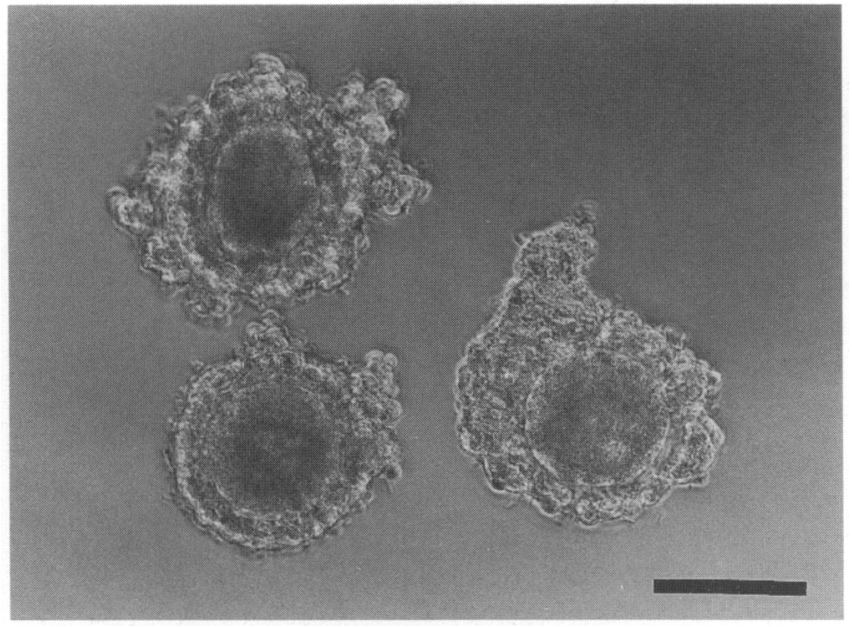

Fig. 2. Pig oocyte-cumulus cell complexes obtained after 16 days of culture. Bar represents $100 \mu \mathrm{m}$.

cavity $(19 \%)$ became two to three times larger than before culture. When these antral follicles were opened with fine forceps, oocytes enclosed by one or two layers of cumulus cells were liberated (Fig. 2).

Oocyte growth was obvious after the culture in vitro. Sixty follicles containing oocytes with diameter of $70-79.5 \mu \mathrm{m}$ were cultured for 16 days, and 26 oocytes $(43 \%)$ were of normal morphology at the end of the culture. The mean diameter of the oocytes increased from $74.0 \pm 3.2 \mu \mathrm{m}$ to $95.3 \pm 7.3 \mu \mathrm{m}$. However, when 84 follicles containing oocytes with diameters of $80-89.5 \mu \mathrm{m}$ were cultured for 12 days, 27 oocytes $(32 \%)$ were normal. The mean diameter increased from $83.9 \pm 3.3 \mu \mathrm{m}$ to $100.5 \pm 6.9 \mu \mathrm{m}$. Moreover, in both groups there were a few oocytes that were near to final size, with diameter greater than $115 \mu \mathrm{m}$.

Histological examination of sections of antral follicles fixed after the growth culture showed that the morphology of follicles developing in ovaries was similar, except that the cultured follicles had no thecal cells (Fig. 3). The pycnotic nuclei of granulosa cells were rarely observed, and the oocytes had normal cytoplasm and an intact germinal vesicle with nucleolus. Another noticeable characteristic of the cultured oocytes was the considerably thinner zona pellucida compared with that of oocytes of similar size that were grown in vivo. A number of oocyte microvilli and processes of the enclosing cumulus cells projected into the zona pellucida (Fig. 4). Contacts between the oocytes and processes of the cumulus cells were observed. An intact nuclear membrane was also visible (not shown).

\section{Maturation of oocytes grown in vitro and in vivo}

The meiotic competence of oocytes grown in vitro was assessed and compared with that of oocytes grown in vivo. A total of 486 follicles containing oocytes with diameters of $70-89.5 \mu \mathrm{m}$ were cultured for 16 days, and the $151(31 \%)$ oocytes recovered were cultured for a further $48 \mathrm{~h}$. A portion of oocytes was fixed and examined before maturation culture, and oocytes were confirmed to be in the germinal vesicle stage. After maturation culture, emission of a first polar body was obvious in four oocytes under the inverted microscope. Cumulus expansion was not observed.

The meiotic competence of the oocytes grown both in vitro and in vivo was correlated with oocyte size (Table 1). After culture for $48 \mathrm{~h}$, all of the oocytes with diameters of $70-89.5 \mu \mathrm{m}$ isolated from ovaries remained at the germinal vesicle stage, indicating that they were meiotically incompetent. In contrast, 6,53 and $77 \%$ of the oocytes grown in vivo that had diameters greater than 90,100 and $110 \mu \mathrm{m}$, respectively, underwent germinal vesicle breakdown. Four and $41 \%$ of the oocytes greater than 100 and $110 \mu \mathrm{m}$, respectively, progressed to metaphase II. However, 6,30 and $60 \%$ of oocytes grown in vitro that were larger than 90,100 and $110 \mu \mathrm{m}$, respectively, underwent germinal vesicle breakdown. None of the oocytes smaller than $90 \mu \mathrm{m}$ resumed meiosis. Progression to metaphase II was observed in $40 \%$ of oocytes with diameters greater than $110 \mu \mathrm{m}$ (Fig. 5). 


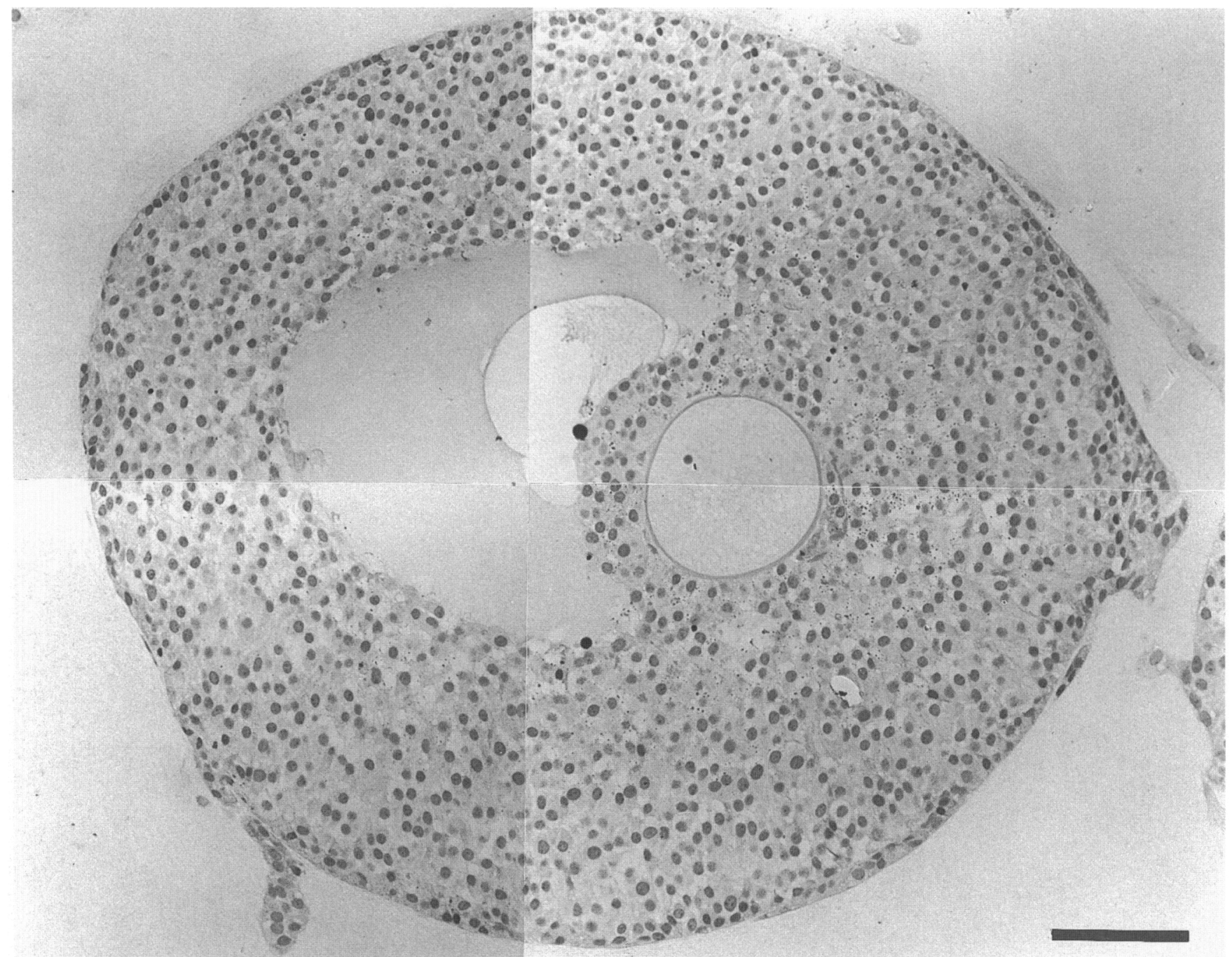

Fig. 3. Histological section of a pig follicle that developed an antral cavity during 12 days of culture in the presence of FSH and oestradiol. Note the absence of thecal cells. The section was stained with periodic acid-Schiff and haematoxylin. Bar represents $100 \mu \mathrm{m}$.

\section{In vitro fertilization}

When oocytes grown in vitro $(n=36)$ were inseminated after $48 \mathrm{~h}$ of maturation culture, sperm penetration was observed in three oocytes. In all of these oocytes, the female pronucleus was observed with sperm head(s) detached from their corresponding sperm tails, whereas enlargement of the sperm head was incomplete (Fig. 6), and emission of the second polar body was never observed.

\section{Discussion}

Growth of oocytes in vitro has been studied in mice (Eppig, 1977; Eppig and Downs, 1987; Eppig and Schroeder, 1989; Hirao et al., 1990; Carroll et al., 1991) and rats (Daniel et al., 1989). Live young were produced from mouse oocytes grown and matured in vitro after transfer to foster mothers (Eppig and Schroeder, 1989; Eppig et al., 1992). However, in vitro culture techniques for growing oocytes of domestic animals have not been established yet.

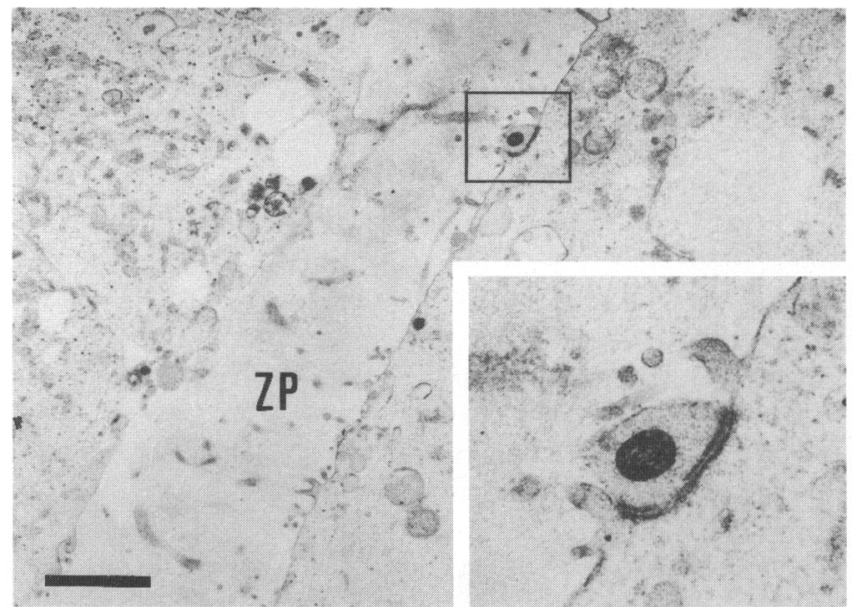

Fig. 4. Electron micrograph of a pig oocyte cultured for 16 days in vitro. Note the presence of a contact (inset) between the oocyte and cumulus cell process that traverses the zona pellucida (ZP). Bar represents $2 \mu \mathrm{m}$. 
Table 1. Relationship between oocyte diameter and meiotic maturation in pig oocytes grown in vivo and in vitro

\begin{tabular}{|c|c|c|c|c|c|c|c|}
\hline \multirow[b]{3}{*}{ Oocyte growth } & \multirow[b]{3}{*}{ Oocyte diameter $(\mu \mathrm{m})$} & \multicolumn{6}{|c|}{ Number of oocytes (\%) } \\
\hline & & \multirow[b]{2}{*}{ Examined } & \multicolumn{4}{|c|}{ Resuming meiosis } & \multirow[b]{2}{*}{ Degenerating } \\
\hline & & & Total & LD & Met 1 & Met II & \\
\hline \multirow[t]{4}{*}{ In vivo } & $70-89.5$ & 34 & $0 \quad(0)$ & $0 \quad(0)$ & $0 \quad(0)$ & $0 \quad(0)$ & $O(0)$ \\
\hline & $90-99.5$ & 32 & $2(6)^{\mathrm{a}}$ & $2(6)$ & $0 \quad(0)$ & $0 \quad(0)$ & $2(6)$ \\
\hline & $100-109.5$ & 47 & $25(53)^{b}$ & $8(17)$ & $15(32)$ & $2(4)^{a}$ & $0(0)$ \\
\hline & $110-120$ & 34 & $26(77)^{b}$ & $7(21)$ & $5(15)$ & $14(41)^{\mathrm{b}}$ & $1(3)$ \\
\hline \multirow[t]{4}{*}{ In vitro } & $70-89.5$ & 35 & $0 \quad(0)$ & $0 \quad(0)$ & $0 \quad(0)$ & $0 \quad(0)$ & $1(3)$ \\
\hline & $90-99.5$ & 51 & $3(6)^{\mathrm{a}}$ & $3(6)$ & $0 \quad(0)$ & $0 \quad(0)$ & $3(6)$ \\
\hline & $100-109.5$ & 50 & $15(30)^{c}$ & $7(14)$ & $8(16)$ & $0 \quad(0)$ & $3(6)$ \\
\hline & $110-120$ & 15 & $9(60)^{\mathrm{bc}}$ & $1(7)$ & $2(13)$ & $6(40)^{\mathrm{b}}$ & $I(7)$ \\
\hline
\end{tabular}

LD: late diakinesis; Met I: metaphase I; Met II: metaphase II.

abc Values with different superscripts in the same column are significantly different. $(P<0.05$, chi-square test).

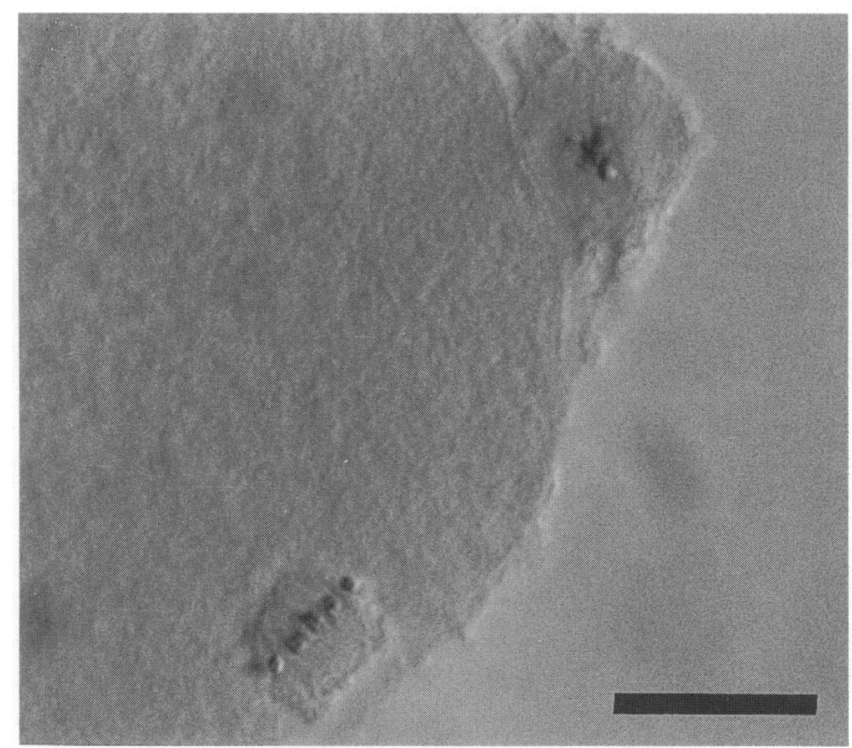

Fig. 5. Photomicrograph of a pig oocyte after maturation culture for $48 \mathrm{~h}$ following 16 days of growth culture. The whole-mounted oocyte was fixed in acetic alcohol and stained with 1\% aceto-orcein. Note the metaphase II spindle and an emitted polar body. Bar represents $20 \mu \mathrm{m}$.

Pig oocytes from antral follicles were used for in vitro maturation experiments (see Moor et al., 1990), in which duration of culture was less than $48 \mathrm{~h}$. In the study reported here, a long-term culture system was developed for pig oocytes at mid-growth phase; and this culture system supported the growth and acquisition of meiotic competence of the oocytes. From studies in rodents, intimate association of granulosa cells with the oocyte was demonstrated as essential for oocyte growth. Results on the growth of pig oocytes reported here are in agreement with the finding that the enclosing granulosa cells are required. In a preliminary experiment, in which preantral pig follicles were settled on the surface of the dish, the surrounding granulosa cells migrated away from the oocyte as reported in mouse oocyte-granulosa cell complexes (Eppig, 1977). Eventually, most of the pig oocytes

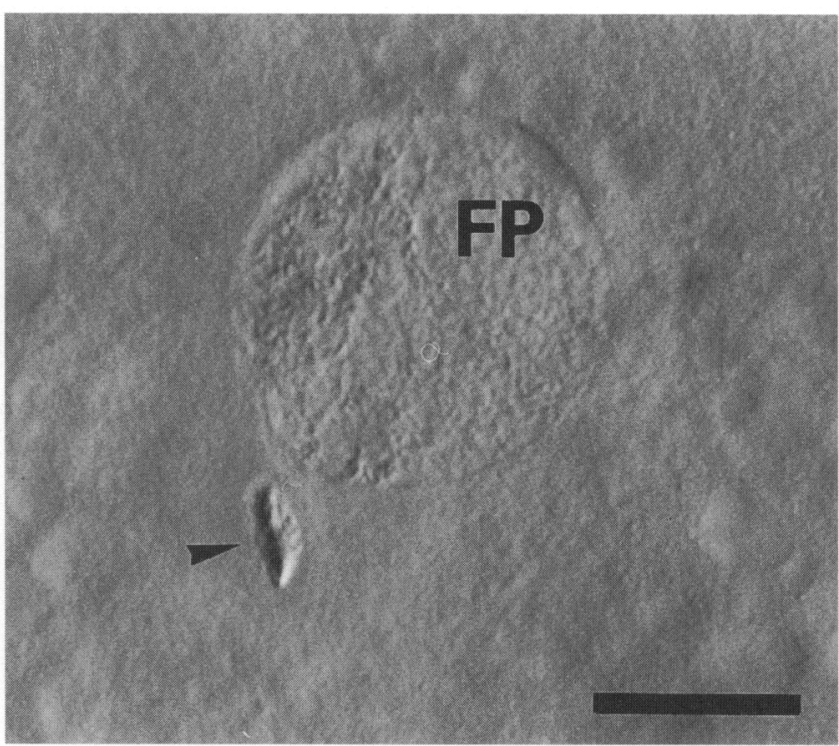

Fig. 6. Photomicrograph of a pig oocyte grown and matured in vitro that was fixed $10 \mathrm{~h}$ after insemination with frozen-thawed epididymal spermatozoa. The whole-mounted oocyte was fixed in acetic alcohol and stained with $1 \%$ aceto-orcein. Within the vitellus, a female pronucleus (FP) and a neighbouring sperm head (arrowhead) are seen. Bar represents $20 \mu \mathrm{m}$.

became denuded, and failed to grow. A culture system using collagen gel which supports mouse follicular development up to multilaminar stages was reported by Torrance et al. (1989). When the preantral pig follicles were embedded in collagen gels, the oocytes were held within the layers of granulosa cells and grew to nearly final size during the culture. Moreover, ultrastructural observation indicated that contacts between the oocytes and processes of cumulus cells were maintained after the culture. Throughout the oocyte growth in the ovary, granulosa cells are coupled with oocytes via heterologous gap junctions (Anderson and Albertini, 1976) through which small molecules such as energy substrates, nucleotides and amino acids are transferred into the oocytes (Heller et al., 1981; 
Brower and Schultz, 1982). It is therefore possible that active metabolic cooperativity is maintained between the pig oocytes and granulosa cells through gap junctions under the culture conditions used in the present study.

In a previous study, we cultured pig preantral follicles for 4 days in the presence and absence of FSH, and found that FSH enhances the viability and growth of oocytes (Hirao et al., 1992). In the study reported here, preantral follicles were cultured for much longer. Not only oocyte growth to nearly final size but also formation of follicular antra were observed in the presence of FSH, whereas antrum formation never occurred in the absence of FSH (data not shown). In hamsters (Roy and Greenwald, 1989) and mice (Nayudu and Osborn, 1992), antrum formation does not occur in preantral follicles unless FSH is present in the culture medium. In rats, FSH stimulates an antrum-like reorganization of the granulosa cells in preantral follicles (Gore-Langton and Daniel, 1990). Antrum formation of preantral follicles in vitro therefore seems to be profoundly affected by FSH. However, it is considered that antrum formation is not necessary for the acquisition of maturational competence of mouse oocytes, and that FSH has little effect on oocyte growth, since oocytes can grow to full size in vitro without formation of an antrum in the absence of hormones (Eppig, 1977). In pigs, the antrum begins to differentiate in follicles with diameters of $0.4-0.8 \mathrm{~mm}$ (Crozet et al., 1981), in which oocytes are still growing and have a limited ability to resume meiosis (Motlik et al., 1984). Our finding of a beneficial effect from FSH on the growth of pig oocytes suggests that follicular differentiation by FSH involves functional changes, which affect the final growth of the oocytes. Alternatively, FSH could stimulate formation of gap junctions between oocytes and granulosa cells, as reported in the homologous gap junctions between porcine granulosa cells cultured with FSH (Amsterdam et al., 1988).

In the study reported here, pig preantral follicles were used, which contained oocytes with diameters of 70-89.5 $\mu \mathrm{m}$. When these oocytes were liberated from the follicles, they did not resume meiosis after maturation culture. Although this finding suggests that the oocytes are meiotically incompetent, they resumed meiosis after growth culture and, moreover, some of them completed the first meiotic division. The meiotic competence of pig oocytes seems to be acquired in two steps as they approach full size in the ovary: (1) resuming meiosis and (2) completing the first meiotic division (Motlik et al., 1984). This assumption was elucidated from evidence that oocytes with a mean diameter of $100 \mu \mathrm{m}$ did not progress beyond metaphase $\mathrm{I}$, whereas those with a mean diameter of $115 \mu \mathrm{m}$ appeared to complete meiotic maturation. In the study reported here, similar results were obtained for oocytes grown both in vitro and in vivo. Meiotic resumption was observed in oocytes with diameter greater than $90 \mu \mathrm{m}$, and the rate of germinal vesicle breakdown increased with increase in oocyte diameter. Completion of the first meiotic division was observed only in those oocytes near full size. Hence, it is clear that oocytes grown under the culture conditions acquired maturational competence sequentially at similar growth stages to those observed in vivo.

In pig oocytes, protein synthesis is required for both germinal vesicle breakdown and the subsequent transition from metaphase I to metaphase II (Fulka et al., 1986; Motlik et al., 1991). Oocytes grown in vitro are therefore equipped to synthesize the protein(s) required for maturation-promoting factor activation (Hashimoto and Kishimoto, 1988).

There have been reports concerning the fertilization of pig oocytes matured in vitro. Since oocytes have a limited ability to form male pronuclei under insufficient maturational conditions (Motlik and Fulka, 1974; Moor ef al., 1990), it has been assumed that, even though oocytes complete the first meiotic division, many do not complete cytoplasmic maturation. This was also observed in the study reported here in which in all oocytes the development of male pronuclei was arrested. This failure was probably due to the inadequacy of the so-called cytoplasmic maturation of oocytes. Considerable improvements in the culture systems for growth of pig oocytes, suggested from mouse studies (Eppig et al., 1990), or for oocyte maturation (Yoshida et al., 1992), could help to ensure normal post-penetration changes in pig oocytes grown and matured in vitro.

The authors thank J. Motlik and J. Fulka for helpful comments on the manuscript. Y. Hirao wishes to thank Y. Shioya for valuable support, and K. Kano for technical assistance.

\section{References}

Amsterdam A, May JV and Schomberg DW (1988) Synergistic effect of insulin and follicle-stimulating hormone on biochemical and morphological differentiation of porcine granulosa cells in vitro Biology of Reproduction 39 379-390

Anderson E and Albertini DF (1976) Gap junctions between the oocyte and companion follicle cells in the mammalian ovary Journal of Cell Biology 71 680-686

Brackett BG and Oliphant G (1975) Capacitation of rabbit spermatozoa in vitro Biology of Reproduction 12 260-274

Brower PT and Schultz RM (1982) Intercellular communication between granulosa cells and mouse oocytes: existence and possible nutritional role during oocyte growth Developmental Biology 90 144-153

Carroll J, Whittingham DG and Wood MJ (1991) Effect of dibutyryl cyclic adenosine monophosphate on granulosa cell proliferation, oocyte growth and meiotic maturation in isolated mouse primary ovarian follicles cultured in collagen gels Journal of Reproduction and Fertility 92 197-207

Crozet N, Motlik J and Szollosi D (1981) Nucleolar fine structure and RNA synthesis in porcine oocytes during the early stages of antrum formation Biology of the Cell 41 35-42

Daniel SAJ, Armstrong DT and Gore-Langton RE (1989) Growth and development of rat oocytes in vitro Gamete Research 24 109-121

Eppig JJ (1977) Mouse oocyte development in vitro with various culture systems Developmental Biology 60 371-388

Eppig JJ and Downs SM (1987) The effect of hypoxanthine on mouse oocyte growth and development in vitro: maintenance of meiotic arrest and gonadotropin-induced oocyte maturation Developmental Biology 119 313-321

Eppig JJ and Schroeder AC (1989) Capacity of mouse oocytes from preantral follicles to undergo embryogenesis and development to live young after growth, maturation, and fertilization in vitro Biology of Reproduction 41 268-276

Eppig JJ, Schroeder AC, van de Sandt JJM, Ziomek CA and Bavister BD (1990) Developmental capacity of mouse oocytes that grow and mature in culture: the effect of modification of the protocol Theriogenology 33 89-100

Eppig JJ, Wigglesworth K and O'Brien MJ (1992) Comparison of embryonic developmental competence of mouse oocytes grown with and without serum Molecular Reproduction and Development 32 33-40

Fulka J Jr, Motlik J, Fulka J and Jilek F (1986) Effect of cycloheximide on nuclear maturation of pig and mouse oocytes Joumal of Reproduction and Fertility $\mathbf{7 7}$ 281-285 
Gore-Langton RE and Daniel SAJ (1990) Follicle-stimulating hormone and estradiol regulate antrum-like reorganization of granulosa cells in rat preantral follicle cultures Biology of Reproduction 43 65-72

Gosden RG and Telfer E (1987) Numbers of follicles and oocytes in mammalian ovaries and their allometric relationships Journal of Zoology 211 169-175

Goto K, Kajihara Y, Kosaka S, Koba M, Nakanishi Y and Ogawa K (1988) Pregnancies after co-culture of cumulus cells with bovine embryos derived from in-vitro fertilization of in-vitro matured follicular oocytes journal of Reproduction and Fertility 83 753-758

Hashimoto $\mathrm{N}$ and Kishimoto T (1988) Regulation of meiotic metaphase by cytoplasmic maturation-promoting factor during mouse oocyte maturation Developmental Biology 126 242-252

Heller DT, Cahill DM and Schultz RM (1981) Biochemical studies of mammalian oogenesis: metabolic cooperativity between granulosa cells and growing mouse oocytes Developmental Biology 84 455-464

Hirao Y, Miyano T and Kato S (1990) Fertilization of in vitro grown mouse oocytes Theriogenology 34 1071-1077

Hirao Y, Miyano T and Kato S (1992) In-vitro growth of porcine oocytes Proceedings of 12 th International Congress on Animal Reproduction The Hague 1 333-335

Mattioli M, Bacci ML, Galeati G and Seren E (1989) Developmental competence of pig oocytes matured and fertilized in vitro Theriogenology 31 1201-1207

Moor RM, Mattioli M, Ding J and Nagai T (1990) Maturation of pig oocytes in vivo and in vitro Journal of Reproduction and Fertility Supplement 40 197-210

Motlik J and Fulka J (1974) Fertilization of pig follicular oocytes cultivated in vitro Journal of Reproduction and Fertility 36 235-237

Motlik J, Crozet N and Fulka J (1984) Meiotic competence in vitro of pig oocytes isolated from early antral follicles Journal of Reproduction and Fertility $72323-328$

Motlik J, Nagai T and Kikuchi K (1991) Resumption of meiosis in pig oocytes cultured with cumulus and parietal granulosa cells: the effect of protein synthesis inhibition Journal of Experimental Zoology 259 386-391
Nagai T, Takahashi T, Masuda H, Shioya Y, Kuwayama M, Fukushima M, Iwasaki $S$ and Hanada A (1988) In-vitro fertilization of pig oocytes by frozen boar spermatozoa Journal of Reproduction and Fertility 84 585-591

Nayudu PL and Osborn SM (1992) Factors influencing the rate of preantral and antral growth of mouse ovarian follicles in vitro Journal of Reproduction and Fertility 95 349-362

Roy SK and Greenwald GS (1989) Hormonal requirements for the growth and differentiation of hamster preantral follicles in long-term culture Journal of Reproduction and Fertility 87 103-114

Schroeder AC and Eppig JJ (1984) The developmental capacity of mouse oocytes that matured spontaneously in vitro is normal Developmental Biology 102 493-497

Staigmiller RB and Moor RM (1984) Effect of follicle cells on the maturation and developmental competence of ovine oocytes matured outside the follicle Gamete Research 9 221-229

Torrance C, Telfer E and Gosden RG (1989) Quantitative study of the development of isolated mouse pre-antral follicles in collagen gel culture Journal of Reproduction and Fertility 87 367-374

Toyoda $Y$ and Chang MC (1974) Fertilization of rat eggs in vitro by epididymal spermatozoa and the development of eggs following transfer Journal of Reproduction and Fertility 36 9-22

Vanderhyden BC and Armstrong DT (1989) Role of cumulus cells and serum on the in vitro maturation, fertilization, and subsequent development of rat oocytes Biology of Reproduction 40 720-728

Yoshida M, Ishigaki K and Pursel VG (1992) Effect of maturation media on male pronucleus formation in pig oocytes matured in vitro Molecular Reproduction and Development 31 68-71 